\title{
Efficiency of Different Selection Criteria for Persistency and Lactation Milk Yield
}

\author{
K. Togashi ${ }^{1}$ and C. Y. Lin ${ }^{2}$ \\ ${ }^{1}$ National Agricultural Research Center for Hokkaido Region, \\ Hitsujigaoka 1, Toyohiraku, Sapporo, Japan 0628555 \\ ${ }^{2}$ Dairy and Swine Research and Development Centre, \\ Agriculture and Agri-Food Canada
}

\begin{abstract}
A conversion formula was developed to convert the genetic covariance matrices of daily yields and of random regression coefficients between 305-d and 335-d production periods under a random regression test day model. Five selection criteria were compared in terms of genetic improvement in persistency and lactation milk: 1) lactation estimated breeding value (EBVL), 2) $\left.\mathrm{P} 6=\sum_{\mathrm{i}=65}^{279}\left(\mathrm{D}_{280}-\mathrm{D}_{\mathrm{i}}\right), 3\right)$ ratio of daily estimated breeding value $(\mathrm{EBV})\left(\mathrm{r}_{280 / 65}=\mathrm{D}_{280} / \mathrm{D}_{65}\right)$, 4) ratio of partial lactation EBV $\left(\mathrm{P}_{280 / 65}=\mathrm{D}_{66-280} / \mathrm{D}_{5-65}\right)$, and 5) differential daily EBV $\left(\mathrm{d}_{65-280}=\mathrm{D}_{65}-\mathrm{D}_{280}\right)$, where $\mathrm{D}_{\mathrm{i}}$ refers to EBV at days in milk (DIM) $i$. Fundamental differences among these 5 selection criteria were interpreted conceptually with a graph. Persistency, defined as $k=$ $\left(\Delta G_{65}-\Delta G_{280}\right) / 215$, was the average daily rate of decline in selection gain from DIM 65 to 280 , which is free from the effect of lactation milk on the rate of decline. Parameter $k$ provides an objective measure of persistency, which increases when $k<0$ and decreases when $k>0$. Of the 5 selection criteria compared, $\mathrm{d}_{65-}$ 280 and P6 achieved greater persistency at the expense of genetic gain in lactation milk, whereas selection based on $\mathrm{EBV}_{\mathrm{L}}$ achieved the highest response in lactation milk, but was coupled with greatest decline in persistency. Selection on $\mathrm{P}_{280 / 65}$ or $\mathrm{r}_{280 / 65}$ improved both lactation milk and persistency and, thus, is recommended for simultaneous improvement of these 2 economically important traits. Further study of the relative economic values of persistency and lactation milk in order to combine both traits into an index for selection decision is warranted.
\end{abstract}

(Key words: persistency, lactation milk, selection criterion, test day model)

Abbreviation key: $\mathbf{R R}$ = random regression.

Received March 13, 2003.

Accepted December 20, 2003.

Corresponding author: K. Togashi; e-mail: tkenji@naro.affrc.go.jp.

\section{INTRODUCTION}

The lactation curve of a dairy cow is determined by a joint effect of genetic and environmental factors. Persistency usually refers to the rate of decline in daily yield after the peak of lactation. There is an inverse relationship between the rate of decline and persistency. The greater the rate of decline, the lower the persistency. A cow with a higher persistency tends to incur less feed, health, and reproduction costs (Zimmermann and Sommer, 1973; Solkner and Fuchs, 1987) and more profit (Dekkers et al., 1998). Therefore, it makes economic sense to study the genetic aspects of the lactation curve to improve persistency. However, persistency should not be achieved at the expense of total lactation milk, as persistency is highly affected by lactation milk. The random regression (RR) test day model permits calculation of daily, partial, and whole lactation EBV, providing a means for evaluating persistency (Schaeffer and Dekkers, 1994; Jamrozik et al., 1997). Gengler (1996) reviewed various criteria of persistency of lactation yields. Swalve and Gengler (1999) classified the criteria into 4 groups: 1) criteria derived from the parameters of the lactation curve; 2) criteria based on ratios between total, partial, peak, and daily yields; 3 ) criteria based on variation of test day yields; and 4) criteria derived from the RR test day model.

Genetic correlations between first lactation yield and various measures of persistency are moderate and favorable (Swalve and Gengler, 1999; Jakobsen et al., 2002), suggesting that it is possible to improve lactation yield and persistency simultaneously. Danell (1982) combined the individual test-day yields into an index to study the possibility of changing the shape of the lactation curve. Ferris et al. (1985) combined yield and the parameters of Wood's lactation curve (Wood, 1967) with some arbitrary weighting factors to select for lactation curve and yield. Persistency and peak yield vary by countries and feeding systems (Zwald et al., 2001), suggesting that the most profitable lactation curve could vary by feeding systems or by countries. Easing stress caused by negative energy balance in early lactation would raise fertility (Butler and Smith, 1989; Sena- 
tore et al., 1996; Loeffler et al., 1999; de Vries et al., 1999). Redistributing the peak yield toward late lactation (i.e., improved persistency) would reduce stress and metabolic disorders in early lactation so that the cow will have higher fertility, thus raising lifetime production.

Index selection based on stage EBV and index selection based on RR coefficients have been presented as 2 equivalent procedures for simultaneous improvement of lactation milk and persistency (Lin and Togashi, 2002; Togashi and Lin, 2003). Both procedures were developed through restricting genetic gains to certain specified lactation stages to achieve the desired curve. The primary objective of this study is to compare the effectiveness of 5 selection criteria in improving total yield and persistency in dairy cows. The secondary objective is to present a procedure for converting the genetic covariance matrices estimated under different production periods (e.g., 305-d vs. 335-d production period).

\section{MATERIALS AND METHODS}

\section{Conversion of Genetic Covariance Matrices Between Different Production Periods}

Although lactation yields are generally standardized on a 305-d basis, the average length of the lactation between countries varies from 209 to $358 \mathrm{~d}$ (ICAR, 2003). Therefore, it is important to develop conversion formulas between different production periods. For example, Pool et al. (2000) estimated genetic covariance matrix of RR coefficients based on 335-d production period rather than on 305-d basis. Obviously, it is useful to develop a mechanism to convert genetic covariance matrices of RR coefficients between 305-d and 335-d production periods.

A Legendre polynomial function of the fifth degree (6 covariates including 0 order) was used to fit the lactation curve in the framework of a RR test day model.

The formula used to standardize DIM (ranging from -1 to 1 ) under a 335 -d production period is

$$
\begin{aligned}
& \text { Standardized DIM }=-1+2(\mathrm{DIM}-5) /(335-5)[1] \\
& =(\mathrm{DIM}-170) / 165 \text {. }
\end{aligned}
$$

Similarly, the standardization of DIM under a 305-d production period is

$$
\begin{gathered}
\text { Standardized DIM }=-1+2(\mathrm{DIM}-5) /(305-5)[2] \\
=(\mathrm{DIM}-155) / 150 .
\end{gathered}
$$

Let matrix $\mathbf{G}^{*}$ be the genetic covariance matrix of daily yields from DIM 5 to 305 under a 335-d production system. Then $\mathbf{G}^{*}$ corresponds to the $(301 \times 301)$ upperleft submatrix of a $(331 \times 331)$ genetic covariance matrix of daily yields from DIM 5 to 335 :

$$
\mathbf{G}^{*}=\Phi^{*} \mathbf{K}_{\mathbf{6}}^{*} \Phi^{* \prime}
$$

where $\Phi^{*}=$ a $301 \times 6$ matrix containing quintic Legendre polynomials with DIM standardized according to Eq. [1] and $\mathbf{K}_{\mathbf{6}}^{*}=$ a $6 \times 6$ genetic covariance matrix of RR coefficients for 335-d production periods.

Similarly, the genetic covariance matrix of daily yields under a 305-d production period $(\mathbf{G})$ can be written as

$$
\mathbf{G}=\Phi \mathbf{K}_{\mathbf{6}} \Phi^{\prime}
$$

where $\Phi=$ a $301 \times 6$ matrix containing quintic Legendre polynomials with DIM standardized according to Eq. [2] and $\mathbf{K}_{\mathbf{6}}=$ a $6 \times 6$ genetic covariance matrix of $R R$ coefficients for a 305-d production period.

Premultiplying and postmultiplying Eq. [4] by $\Phi^{\prime}$ and $\Phi$, respectively, leads to

$$
\Phi^{\prime} \mathrm{G} \Phi=\Phi^{\prime} \Phi \mathrm{K}_{6} \Phi^{\prime} \Phi
$$

Re-arranging this formula leads to $\mathbf{K}_{\mathbf{6}}=\left(\Phi^{\prime} \Phi\right)^{-1}$ $\Phi^{\prime} \mathbf{G} \boldsymbol{\Phi}\left(\boldsymbol{\Phi}^{\prime} \boldsymbol{\Phi}\right)^{-1}$. It is expected that $\mathbf{G}=\mathbf{G}^{*}=\Phi^{*} \mathbf{K}_{\mathbf{6}}^{*} \Phi^{* \prime}$. Therefore,

$$
\mathbf{K}_{\mathbf{6}}=\left(\Phi^{\prime} \boldsymbol{\Phi}\right)^{-1} \Phi^{\prime} \Phi^{*} \mathbf{K}_{\mathbf{6}}^{*} \Phi^{* \prime} \boldsymbol{\Phi}\left(\Phi^{\prime} \Phi\right)^{-1},
$$

and subsequently,

$$
\mathbf{K}_{\mathbf{6}}^{*}=\left(\Phi^{\prime} \Phi^{*}\right)^{-1} \Phi^{\prime} \Phi \mathbf{K}_{\mathbf{6}} \Phi^{\prime} \Phi\left(\Phi^{* \prime} \Phi\right)^{-1}
$$

Equation (5) was used to convert the genetic covariance matrix of RR coefficients from a 335-d (Pool and Meuwissen, 2001) to 305-d production period in this study.

\section{Selection Criteria Compared}

Selection based on lactation EBV $\left(E B V_{L}\right)$. Current selection under $R R$ test day model is based on lactation $\mathrm{EBV}$, i.e., $\mathrm{EBV}_{\mathrm{L}}=\mathbf{1}^{\prime} \boldsymbol{\Phi} \alpha$, where $\mathbf{1}$ is a summing vector, $\Phi$ is the Legendre polynomial matrix of a whole lactation, and $\alpha$ is a vector of RR coefficients. The correlated response in $\operatorname{DIM~i~}\left(\Delta \mathrm{G}_{\mathrm{i}}, \mathrm{i}=5,6, \ldots 305\right)$ to selection on $\mathrm{EBV}_{\mathrm{L}}$ is

$$
\Delta \mathrm{G}_{\mathrm{i}}=\mathrm{b}_{\mathrm{D}_{\mathrm{i}} \cdot \operatorname{EBV}_{\mathrm{L}}}(\text { sel. diff. })=\operatorname{Cov}\left(\mathrm{D}_{\mathrm{i}}, \mathrm{EBV}_{\mathrm{L}}\right)\left(\overline{\mathrm{i}} / \sigma_{\mathrm{EBV}_{\mathrm{L}}}\right)
$$

where $b_{D_{i} \cdot E B V}$ is the regression coefficient of EBV at $\operatorname{DIM}_{\mathrm{i}}\left(\mathrm{D}_{\mathrm{i}}\right)$ on lactation EBV $\left(\mathrm{EBV}_{\mathrm{L}}\right), \overline{\mathrm{i}}$ the intensity of selection, and $\sigma_{\mathrm{EBV}_{\mathrm{L}}}$ the standard deviation of $\mathrm{EBV}_{\mathrm{L}}$. 
The daily correlated responses to selection on $\mathrm{EBV}_{\mathrm{L}}$ can be expressed in a matrix form:

$$
\underline{\Delta}_{\mathrm{L}}=\mathbf{G 1}\left(\overline{\mathrm{i} /} \sigma_{\mathrm{EBV}_{\mathrm{L}}}\right)
$$

where $\Delta_{\mathrm{L}}$ is a $301 \times 1$ vector of daily responses from DIM 5 to $305, \mathbf{G}$ is the $301 \times 301$ genetic covariance matrix of daily yields from DIM 5 to 305 , and $\sigma_{\mathrm{EBV}_{\mathrm{L}}}=$

$\sqrt{\mathbf{1}^{\prime} \boldsymbol{\Phi} \mathbf{K}_{\mathbf{6}} \boldsymbol{\Phi}^{\prime} \mathbf{1}}$. The total lactation response is $\Delta \mathrm{G}_{T \cdot E B V_{\mathrm{L}}}=\mathbf{1}^{\prime} \Delta_{L}$.

Selection based on differential EBV. The difference between EBV at 2 DIM is defined as $d_{65-280}=D_{65}$ $-\mathrm{D}_{280}$, where 65 is DIM at peak based on the report of Pool and Meuwissen (2001). Because $\mathrm{D}_{65}$ is greater than $\mathrm{D}_{280}$, the smaller the difference $\left(\mathrm{d}_{65-280}\right)$, the greater the persistency. When selection is on $\mathrm{d}_{65-280}$, the correlated response in DIM $\mathrm{j}$ is

$$
\Delta \mathrm{G}_{\mathrm{j}}=\operatorname{Cov}\left(\mathrm{d}_{65-280}, \mathrm{D}_{\mathrm{j}}\right)\left(\overline{\mathrm{i} /} \sigma_{\mathrm{d}_{65-280}}\right) .
$$

In matrix form, the daily correlated responses from DIM 5 to 305 to selection on $d_{65-280}$ are

$$
\left.\underline{\Delta}_{\mathrm{d}}=\left(\mathbf{G}_{65}-\mathbf{G}_{280}\right) \stackrel{-}{\mathrm{i} / \sigma_{\mathrm{d}_{65-280}}}\right)
$$

where $\sigma_{\mathrm{d}_{65-280}}=\sqrt{\sigma_{\mathrm{D}_{65}}^{2}+\sigma_{\mathrm{D}_{280}}^{2}-2 \sigma_{\mathrm{D}_{65,280}}}, \Delta_{\mathrm{d}}$ is a $301 \times$ 1 vector containing daily responses from DIM 5 to 305 , and $\mathbf{G}_{65}$ and $\mathbf{G}_{280}$ are the columns of the genetic covariance matrix of daily yields $(\mathbf{G})$ corresponding to DIM 65 and 280, respectively. Note that the first column of $\mathbf{G}$ (i.e., $\mathbf{G}_{\mathbf{1}}$ ) contains the (co)variances between DIM 5 and each day of the lactation; so, $\mathbf{G}_{65}$ and $\mathbf{G}_{280}$ are columns 61 and 276 of $\mathbf{G}$, respectively. Total correlated response to selection on $\mathrm{d}_{65-280}$ is equal to $\Delta \mathrm{G}_{T \cdot \mathrm{d}_{65-280}}=\mathbf{1}^{\prime} \underline{\Delta}_{\mathrm{d}}$.

Selection based on ratio of daily EBV. According to Taylor series expansion (Mood et al., 1987), a ratio (say $\mathrm{r}=x / y$ ) can be approximated as follows:

$$
\begin{aligned}
\mathrm{r}=\mathrm{r}\left(\mu_{x}, \mu_{y}\right)+ & \left.\frac{\partial r}{\partial x}\right|_{\mu_{x}, \mu_{y}}\left(x-\mu_{x}\right)+\left.\frac{\partial r}{\partial y}\right|_{\mu_{x}, \mu_{y}}\left(y-\mu_{y}\right) \\
& =\frac{\mu_{x}}{\mu_{y}}+\frac{1}{\mu_{y}} x-\frac{\mu_{x}}{\mu_{y}^{2}} y .
\end{aligned}
$$

It follows that $\mathrm{V}(\mathrm{r})=\frac{1}{\mu_{y}^{2}} \sigma_{x}^{2}-2 \frac{\mu_{x}}{\mu_{y}^{3}} \sigma_{x y}+\frac{\mu_{x}^{2}}{\mu_{y}^{4}} \sigma_{y}^{2}$, and $\operatorname{Cov}(r$, $z)=\frac{1}{\mu_{y}} \sigma_{x z}-\frac{\mu_{x}}{\mu_{y}^{2}} \sigma_{y z}$
Let $\mathrm{D}_{i}$ be the daily EBV of DIM $i$. The ratio of $\mathrm{D}_{280}$ to $D_{65}$ is $r_{280 / 65}=D_{280} / D_{65}$. By this definition, a large ratio is desirable for persistency. When selection is based on $\mathrm{r}_{280 / 65}$, the total correlated response $\left(\Delta G_{T \cdot \mathrm{r}_{280 / 65}}\right)$ is

$$
\Delta \mathrm{G}_{T \cdot r_{280 / 65}}=\sum_{\mathrm{j}=5}^{305} \Delta G_{\mathrm{j}}=\sum_{\mathrm{j}=5}^{305} \operatorname{Cov}\left(\mathrm{r}_{280 / 65}, \mathrm{D}_{\mathrm{j}}\right)\left(\overline{\mathrm{i} / \sigma_{r_{280 / 65}}}\right)
$$

where

$$
\begin{gathered}
\sum_{j=5}^{305} \operatorname{Cov}\left(r_{280 / 65}, \mathrm{D}_{j}\right)=\frac{1}{\overline{\mathrm{D}}_{65}} \sum_{j=5}^{305} \sigma_{\mathrm{D}_{280, j}}-\frac{\overline{\mathrm{D}}_{280}^{305} \overline{\mathrm{D}}_{65}^{2} \sum_{j=5} \sigma_{\mathrm{D}_{65, j}}}{\overline{\mathrm{D}}_{65}} \mathbf{1}^{\prime} \mathbf{G}_{\mathbf{2 8 0}}-\frac{\overline{\mathrm{D}}_{280}}{\overline{\mathrm{D}}_{65}^{2}} \mathbf{1}^{\prime} \mathbf{G}_{\mathbf{6 5}}
\end{gathered}
$$

and

$$
\sigma_{r_{280 / 65}}=\sqrt{\frac{1}{\overline{\mathrm{D}}_{65}^{2}} \sigma_{\mathrm{D}_{280}}^{2}-2 \frac{\overline{\mathrm{D}}_{280}}{\overline{\mathrm{D}}_{65}^{3}} \sigma_{\mathrm{D}_{65,280}}+\frac{\overline{\mathrm{D}}_{280}^{2}}{\overline{\mathrm{D}}_{65}^{4}} \sigma_{\mathrm{D}_{65}}^{2}} .
$$

Note that the linear index derived to maximize the genetic value of $\mathrm{r}=\mu_{x} / \mu_{y}+\frac{1}{\mu_{y}} x-\frac{\mu_{x}}{\mu_{y}^{2}} y$ is identical to that developed by Lin (1980) to maximize the genetic value of $\mathrm{r}=x-\frac{\mu_{x}}{\mu_{y}} y$. Lin (1980) presented a linear index approach to sidestep the problems of estimating the genetic parameters of a ratio and to maximize the response in a ratio.

Selection based on ratio of partial lactation $\boldsymbol{E B V}$. The ratio of partial lactation EBV is defined as $\mathrm{P}_{280 / 65}=\mathrm{D}_{66 \sim 280} / \mathrm{D}_{5-65}$, where $\mathrm{D}_{66 \sim 280}$ is the cumulative EBV from DIM 66 to 280 with the symbol “ " denoting the range. On the basis of Taylor series expansion of a ratio as shown previously,

$$
\begin{aligned}
\mathrm{V}\left(\mathrm{P}_{280 / 65}\right)= & \frac{1}{\overline{\mathrm{D}}_{5 \sim 65}^{2}} \sigma_{\mathrm{D}_{66-280}}^{2}-2 \frac{\overline{\mathrm{D}}_{66-280}}{\overline{\mathrm{D}}_{5 \sim 65}^{3}} \sigma_{\mathrm{D}_{5-65,66-280}} \\
& +\frac{\overline{\mathrm{D}}_{66-280}^{2}}{\overline{\mathrm{D}}_{5 \sim 65}^{4}} \sigma_{\mathrm{D}_{5-65}}^{2} \text { and } \\
\operatorname{Cov}\left(\mathrm{P}_{280 / 65}, \mathrm{D}_{\mathrm{j}}\right)= & \frac{1}{\overline{\mathrm{D}}_{5 \sim 65}} \sigma_{\mathrm{D}_{66-280, j}}-\frac{\overline{\mathrm{D}}_{66-280}}{\overline{\mathrm{D}}_{5 \sim 65}^{2}} \sigma_{\mathrm{D}_{5-65, j}}
\end{aligned}
$$

where

$$
\begin{gathered}
\sigma_{\mathrm{D}_{66-280}}^{2}=\mathbf{1}^{\prime} \mathbf{G}_{66 \sim 280,66 \sim 280} \mathbf{1}, \\
\sigma_{\mathrm{D}_{5 \sim 65,66-280}}^{2}=\mathbf{1}^{\prime} \mathbf{G}_{5 \sim 65,66 \sim 280} \mathbf{1}, \\
\sigma_{\mathrm{D}_{5 \sim 65}}^{2}=\mathbf{1}^{\prime} \mathbf{G}_{5 \sim 65,5 \sim 65} \mathbf{1},
\end{gathered}
$$




$$
\begin{gathered}
\sigma_{\mathrm{D}_{66 \sim 280, \mathrm{j}}}=\mathbf{1}^{\prime} \mathbf{G}_{66 \sim 280, \mathrm{j}}, \text { and } \\
\sigma_{\mathrm{D}_{5 \sim 65, \mathrm{j}}}=\mathbf{1}^{\prime} \mathbf{G}_{5 \sim 65, \mathrm{j}} .
\end{gathered}
$$

Correlated response in DIM $\mathrm{j}$ to selection on $\mathrm{P}_{280 / 65}$ is $\Delta \mathrm{G}_{\mathrm{j}}=\operatorname{Cov}\left(\mathrm{P}_{280 / 65}, \frac{\mathrm{D}_{\mathrm{j}}}{305}\right)\left(\mathrm{i} / \sigma_{\mathrm{P}_{280 / 65}}\right)$. Total response in lactation is $\Delta G_{T \cdot \mathrm{P}_{280 / \mathrm{i}}}=\sum_{\mathrm{j}=5} \Delta G_{\mathrm{j}}$.

Selection based on P6. Jakobsen et al. (2002) defined $\mathrm{P} 5=\sum_{\mathrm{i}=60}^{279}\left(\mathrm{D}_{\mathrm{i}}-\mathrm{D}_{280}\right)$ with a large value of $\mathrm{P} 5$, indicating a high persistency. In contrast to their report, the initial results of this study indicated that selection should be for a small P5 rather than a large P5 to improve persistency. This study defined $\mathrm{P} 6$ as P6 = $\sum_{\mathrm{i}=65}^{279}\left(\mathrm{D}_{280}-\mathrm{D}_{\mathrm{i}}\right)=215 \mathrm{D}_{280}-\sum_{\mathrm{i}=65}^{279} \mathrm{D}_{\mathrm{i}}$, with a large value of P6 indicating a high persistency. The DIM at peak was around 65 (Pool and Meuwissen, 2001). Correlated response in DIM $\mathrm{j}$ to selection on $\mathrm{P} 6$ is $\Delta G_{\mathrm{j}}=$ $\left(215 \sigma_{\mathrm{D}_{\mathrm{j}, 280}}-\sum_{\mathrm{i}=65}^{279} \sigma_{\mathrm{D}_{\mathrm{j}, \mathrm{i}}}\right)\left(\mathrm{i} / \sigma_{\mathrm{P} 6}\right)$ where $\sigma_{\mathrm{P} 6}^{2}=215^{2} \mathbf{G}_{280,280}+$ $\mathbf{1}^{\prime} \mathbf{G}_{65-279,65 \sim 279} \mathbf{1}-2 \times 215 \times \mathbf{1}^{\prime} \mathbf{G}_{65 \sim 279,280}$. Total response to selection on $\mathrm{P} 6$ is $\Delta G_{\mathrm{T} \cdot \mathrm{P} 6}=\sum_{\mathrm{j}=5}^{305} \Delta G_{\mathrm{j}}$.

\section{Basis for Comparison of Selection Criteria}

The rate of decline between 2 consecutive DIM after selection is

$$
\begin{gathered}
\left(\overline{\mathrm{D}}_{\mathrm{i}}+\Delta \mathrm{G}_{\mathrm{i}}\right)-\left(\overline{\mathrm{D}}_{\mathrm{i}+1}+\Delta \mathrm{G}_{\mathrm{i}+1}\right)=\left(\overline{\mathrm{D}}_{\mathrm{i}}-\overline{\mathrm{D}}_{\mathrm{i}+1}\right) \\
+\left(\Delta \mathrm{G}_{\mathrm{i}}-\Delta \mathrm{G}_{\mathrm{i}+1}\right)=\mathrm{k}_{0}+\mathrm{k}_{1}
\end{gathered}
$$

where $k_{0}$ is the rate of decline before selection and $k_{1}$ is the genetic change in rate of decline because of selection.

In this study, persistency $(k)$ is defined as the average daily rate of decline in genetic gain from DIM 65 (peak) to 280 :

$$
k=\frac{\sum_{\mathrm{i}=65}^{279}\left(\Delta \mathrm{G}_{\mathrm{i}}-\Delta \mathrm{G}_{\mathrm{i}+1}\right)}{280-65}=\frac{\Delta \mathrm{G}_{65}-\Delta \mathrm{G}_{280}}{215} .
$$

By this definition, the value of $k$ is not a function of EBV and, thus, is free from the effect of lactation milk on the rate of decline. Therefore, parameter $k$ provides an objective measure of persistency. Note that parameter $k$ is in inverse relationship to persistency; the

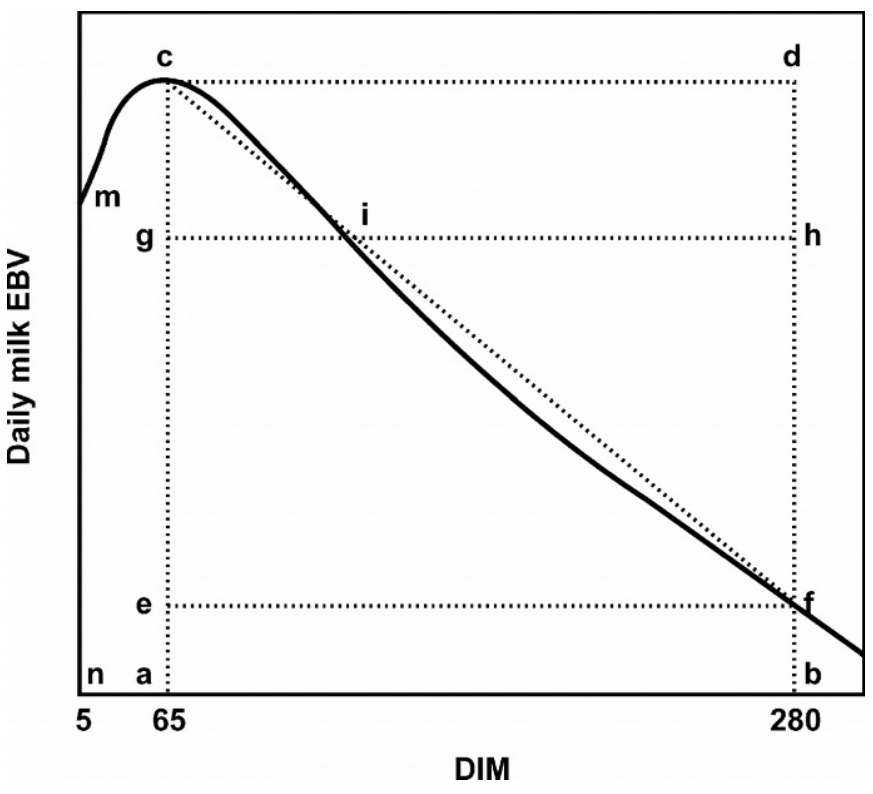

Figure 1. Interrelationship among different selection criteria. $\mathrm{a}=$ DIM $65, \mathrm{~b}=$ DIM 280, $\mathrm{c}=$ milk yield at DIM $65, \mathrm{f}=$ milk yield at DIM $280, \mathrm{~m}=$ milk yield at DIM 5 , and $\mathrm{n}=$ DIM 5 .

smaller the value $k$, the greater the improvement of persistency.

Let $m$ be the midpoint between DIM 65 (peak) and 280 . When $\Delta G_{m \sim 280}>\Delta G_{65 \sim m}$, persistency improves. If $\Delta G_{m \sim 280}=\Delta G_{65 \sim m}$, persistency remains unchanged. If $\Delta G_{m \sim 280}<\Delta G_{65 \sim m}$, persistency deteriorates. Total lactation response, genetic response for each stage of the lactation, and average daily genetic gains were used to assess the improvement of persistency associated with each selection criterion. Selection intensity (i) is set at 0.1 for all criteria to compare selection responses. Genetic covariance matrix of daily yields from DIM 5 to $305(\mathbf{G})$ was calculated as $\mathbf{G}=\boldsymbol{\Phi} \mathbf{K} \boldsymbol{\Phi}^{\prime}$, where $\mathbf{K}$ is a $6 \times$ 6 genetic covariance matrix of RR coefficients and $\Phi$ is a $301 \times 6$ Legendre polynomial matrix. Matrix $\mathbf{K}^{*}$ of a 335-d production system (Pool and Meuwissen, 2001) was converted into matrix $\mathbf{K}$ of a 305 -d production system for this study according to conversion Eq. [5].

\section{Graphic Depiction of Different Selection Criteria}

The interrelationship among differential daily EBV $\left(\mathrm{d}_{65-280}=\mathrm{D}_{65}-\mathrm{D}_{280}\right)$, ratio of daily $\mathrm{EBV}\left(\mathrm{r}_{280 / 65}=\mathrm{D}_{280} /\right.$ $\left.\mathrm{D}_{65}\right)$, ratio of partial lactation $\mathrm{EBV}\left(\mathrm{P}_{280 / 65}=\mathrm{D}_{66 \sim 280} / \mathrm{D}_{5 \sim 65}\right)$ and P6 $\left(\sum_{i=65}^{279}\left(D_{280}-D_{i}\right)\right)$ was depicted graphically in Figure 1. Criterion $\mathrm{d}_{65-280}$ refers to the difference in height between $c$ and $e$ (Figure 1). Therefore, selecting for a smaller difference between $c$ and $e$ tends to reduce the 
triangle cef, as the length between DIM 65 and 280 is a constant. Criterion $\mathrm{r}_{280 / 65}$ can be linearly approximated as $\mathrm{D}_{280}-\left(\overline{\mathrm{D}}_{280} / \overline{\mathrm{D}}_{65}\right) \mathrm{D}_{65}$ (Lin, 1980). Let $g$ be the value of $\left(\overline{\mathrm{D}}_{280} / \overline{\mathrm{D}}_{65}\right) \mathrm{D}_{65}$ on DIM 65 in Figure 1. The ratio of $\mathrm{r}_{280 / 65}$ would improve persistency as long as the height of $e$ (i.e., $f$ ) increases at a faster rate than the height of $g$. Thus, selecting for a larger ratio of $r_{280 / 65}$ would reduce the difference in height between $g$ and $e$ in Figure 1, thus implying selection for a smaller area of the rectangle gefh.

The rate of decline from peak to DIM 280 is the definition of persistency. It is more closely related to the triangle cef than to the trapezoid gefi, which is part of triangle cef as well as part of rectangle gefh. Therefore, criterion $\mathrm{d}_{65-280}$ will bring about a larger response in persistency than will criterion $\mathrm{r}_{280 / 65}$. Conversely, the area of cef is more closely related to lactation milk than that of gef because the triangle cef is always larger than the triangle gef. Therefore, improvement of persistency by reducing the triangle cef through $\mathrm{d}_{65-280}$ will decrease lactation milk more than reducing the triangle gef through $\mathrm{r}_{280}$ 65. Criterion P6 selects for a small area of cef, which can be reduced by increasing the height of $f$ (i.e., increasing DIM 280), decreasing the height of $c$ (i.e., decreasing the peak DIM 65), or a combination of both.

Criterion $d_{65-280}$ assigns equal weights (1:1) between $\mathrm{D}_{280}$ and $\mathrm{D}_{65}$. Criterion $\mathrm{r}_{280 / 65}$ can be linearly expressed as $\mathrm{D}_{280}-\left(\overline{\mathrm{D}}_{280} / \overline{\mathrm{D}}_{65}\right) \mathrm{D}_{65}$ (Lin, 1980), indicating that the weighting factors between $\mathrm{D}_{280}$ and $\mathrm{D}_{65}$ are $1: \overline{\mathrm{D}}_{280} / \overline{\mathrm{D}}_{65}$. Because $\overline{\mathrm{D}}_{280} / \overline{\mathrm{D}}_{65}$ is $<1$, criterion $\mathrm{r}_{280 / 65}$ places greater weight on $\mathrm{D}_{280}$ than on $\mathrm{D}_{65}$. Implicitly, $\mathrm{r}_{280 / 65}$ aims to improve lactation milk and persistency mainly by increasing $\mathrm{D}_{280}$. Similarly, criterion $\mathrm{P}_{280 / 65}$ can be linearly represented as $\mathrm{D}_{66-280}-\frac{\overline{\mathrm{D}}_{66-280}}{\overline{\mathrm{D}}_{5-65}} \mathrm{D}_{5 \sim 65}$. As shown in Figure $1, D_{5-65}$ is equal to the area of mnac, and $D_{66-280}$ is equal to $\left(a b f c-\mathrm{D}_{65}\right)$. Because $\frac{\overline{\mathrm{D}}_{66-280}}{\overline{\mathrm{D}}_{5-65}}$ is $>1$, criterion $\mathrm{P}_{280 / 65}$ puts greater weight on $\mathrm{D}_{5 \sim 65}$ than on $\mathrm{D}_{66-280}$ to increase the value of $\mathrm{P}_{280 / 65}$.

\section{RESULTS AND DISCUSSION}

\section{Conversion of Covariance Matrix of RR Coefficients Between Production Systems}

Equations [5] and [6] were developed to convert the genetic covariance matrices of $\mathrm{RR}$ coefficients between 305-d production period $\left(\mathbf{K}_{\mathbf{6}}\right)$ and 335-d production pe$\operatorname{riod}\left(\mathbf{K}_{\mathbf{6}}^{*}\right)$. The same principle applies to the development of conversion formulas between any 2 different production periods. Once $\mathbf{K}_{\mathbf{6}}$ and $\mathbf{K}_{\mathbf{6}}^{*}$ are converted, the genetic covariance matrix of daily yields can be computed subsequently according to Eq. [3] and [4]. Matrix $\mathbf{K}_{\mathbf{6}}^{*}$ (Pool and
Meuwissen, 2001), under a 335-d production system, was converted to $\mathbf{K}_{\mathbf{6}}$, which in turn was used to compute genetic covariance matrix of daily yields $(\mathbf{G})$ under a 305-d system. This $\mathbf{G}$ matrix was found to be identical to the $301 \times 301$ upper-left submatrix of the $331 \times 331$ full genetic covariance matrix of daily yields, thus confirming the validity of conversion between $\mathbf{K}_{\mathbf{6}}$ and $\mathbf{K}_{\mathbf{6}}^{*}$. Although the $\mathbf{G}$ matrix on a 305-d basis can be extracted directly from that on a 335-d basis, the conversion formula is needed to convert the $\mathbf{G}$ matrix from a 305-d basis to a 335-d basis for comparison purposes. However, the $\mathbf{K}$ matrix of RR coefficients is needed for conversion between 305-d and 335-d systems because the $\mathbf{K}$ matrix on a 305-d basis is not a subset of that on a 335-d basis.

\section{Comparison of Selection Criteria}

Persistency is affected by the lactation yield genetically (Jamrozik et al., 1998; Swalve and Gengler, 1999; Jakobsen et al., 2002). For the purpose of comparing the effectiveness of different selection criteria in improving persistency, this study defined the persistency parameter $(k)$ as the average daily rate of decline in genetic gain from DIM 65 (peak) to DIM 280. Given a fixed amount of cumulative genetic gain from DIM 65 to 280 , a selection criterion that yields a smaller value of $k$ will achieve a greater improvement in persistency. Persistency improves when $k$ is negative (i.e., $\Delta \mathrm{G}_{65}<\Delta \mathrm{G}_{280}$ ), deteriorates when $k$ is positive (i.e., $\Delta \mathrm{G}_{65}>\Delta \mathrm{G}_{280}$ ), and remains unchanged when $k$ is equal to 0 (i.e., $\Delta \mathrm{G}_{65}=\Delta \mathrm{G}_{280}$ ). The value $k$ was defined independently of the lactation yield before selection and is, thus, free from the effect of lactation milk on the rate of decline. Therefore, parameter $k$ provides an objective measure of persistency. The average daily rate of decline in genetic gain from DIM 65 to 280 was divided into 3 intervals: DIM 65 to 89, DIM 90 to 210 , and DIM 211 to 280 . Genetic responses in persistency and lactation milk from the 5 selection criteria are given in Table 1.

As shown in Table 1, conventional selection based on $\mathrm{EBV}_{\mathrm{L}}$ was expected to raise the lactation milk by $67 \mathrm{~kg}$ EBV and to decrease persistency because of the positive value of $k$. Although selection for a large value of P6 = 279

$\sum_{\mathrm{i}=65}\left(\mathrm{D}_{280}-\mathrm{D}_{\mathrm{i}}\right)$ increased persistency, it incurred the greatest loss of lactation milk by $26.53 \mathrm{~kg}$ EBV (Table 1). The improvement in persistency caused by $\mathrm{P} 6$ is in agreement with graphic interpretation of P6 in Figure 1. The report of Jakobsen et al. (2002) about P5 was misleading because selection should be for a lower value of P5 rather than a higher value for improvement of persistency.

Of the 5 selection criteria studied, criteria $\mathrm{d}_{65-280}$ (i.e., $\mathrm{D}_{65}-\mathrm{D}_{280}$ ) and $\mathrm{P} 6$ resulted in greater improvement in 
Table 1. Responses in persistency and lactation milk from 5 selection criteria (unit $=\mathrm{kg}$ ).

\begin{tabular}{llllrl}
\hline & \multicolumn{5}{c}{ Criterion } \\
\cline { 2 - 5 } Response & $\mathrm{D}_{65}^{2}-\mathrm{D}_{280}$ & $\mathrm{D}_{280} / \mathrm{D}_{65}$ & $\mathrm{D}_{66-280} / \mathrm{D}_{5-65}$ & $\mathrm{EBV}_{3}^{\mathrm{L}}$ & $\mathrm{P}^{4}$ \\
\hline $\mathrm{k}=\left(\Delta \mathrm{G}^{1}{ }_{65}-\Delta \mathrm{G}_{280}\right) / 215$ & -0.00091 & -0.00064 & -0.00053 & 0.00018 & -0.00082 \\
$\left(\Delta \mathrm{G}_{65}-\Delta \mathrm{G}_{89}\right) / 24$ & -0.00123 & -0.00124 & -0.00152 & -0.00037 & -0.00061 \\
$\left(\Delta \mathrm{G}_{90}-\Delta \mathrm{G}_{210}\right) / 120$ & -0.00086 & -0.00067 & -0.00060 & 0.00007 & -0.00073 \\
$\left(\Delta \mathrm{G}_{211}-\Delta \mathrm{G}_{280}\right) / 69$ & -0.00088 & -0.00037 & -0.00005 & 0.00057 & -0.00107 \\
$\Delta \mathrm{EBV}_{\mathrm{L}}$ & -13.42 & 36.77 & 34.19 & 67.17 & -26.53 \\
\hline
\end{tabular}

${ }^{1} \Delta \mathrm{G}_{\mathrm{i}}=$ genetic response in DIM $\mathrm{i}$.

${ }^{2} \mathrm{D}_{\mathrm{i}}=\mathrm{EBV}$ on DIM i.

${ }^{3} \mathrm{EBV}_{\mathrm{L}}=$ lactation EBV.

${ }^{4} \mathrm{P} 6=\sum_{\mathrm{i}=65}^{279}\left(\mathrm{D}_{280}-\mathrm{D}_{\mathrm{i}}\right)$.

persistency mainly because both criteria are more related to the definition of persistency $k=\left(\Delta G_{65}-\Delta G_{280}\right) /$ 215 than were the other three criteria compared. However, both $\mathrm{d}_{65-280}$ and P6 incurred greater loss in lactation milk by 13.4 and $26.5 \mathrm{~kg}$ EBV, respectively (Table 1). This result is in agreement with the graphic depiction of selection criteria in the previous section. Therefore, both criteria are not a viable approach for simultaneous improvement of persistency and lactation milk. Dekkers et al. (1996) recommended the use of differential yield between DIM 60 and 280 for genetic evaluation for persistency of lactation because it was less correlated with 305-d yield.

The response in persistency to selection based on the ratio $D_{280} / D_{65}$ is negative, indicating an improvement of persistency. In addition, this criterion resulted in a gain of $37 \mathrm{~kg} \mathrm{EBV}$ in lactation milk (Table 1). The increase in lactation milk is because a relatively larger weighting factor was placed on the increase in $D_{280}$ than on the decrease $\mathrm{D}_{65}$, as graphically depicted earlier $\left(1: \overline{\mathrm{D}}_{280} /\right.$ $\overline{\mathrm{D}}_{65}$ ). Selection on the ratio of partial lactation EBV $\left(\mathrm{D}_{66-280} / \mathrm{D}_{5 \sim 65}\right)$ increased persistency and increased lactation milk by $34 \mathrm{~kg}$ EBV. Note that the smaller the parameter $k$, the greater the increase in persistency. As shown in Table 1, all of the 5 selection criteria had a smaller genetic gain per day in stage DIM 65 to 89 than in stage DIM 90 to 210, which in turn had a smaller gain than in stage DIM 211 to 280 . This indicates that persistency was mainly achieved in stage DIM 65 to 89, and, thus, more weights need to be placed on stages DIM 90 to 210 and DIM 211 to 280 to further reduce the slope of the lactation curve.

The correlated gains on DIM 5, 30, 60, 65, 90, 120, 180, 240, 280, and 305 are given in Table 2 and Figure 2 . The daily genetic gains on DIM 5 through 220 caused by selection on $D_{65}-D_{280}$ were negative and then became positive from DIM 220 onward. In contrast, selection based on the ratio of daily EBV $\left(\mathrm{r}_{280 / 65}\right)$ increased daily EBV throughout the whole lactation, particularly toward the end of lactation. Daily genetic response to selection on ratio of partial lactation $\mathrm{EBV}\left(\mathrm{P}_{280 / 65}\right)$ was negative from DIM 5 to 34 and then increased steadily from DIM 35 to 200 and tapered off from DIM 200 onward (Figure 2). Similar trend in daily response was observed for criterion $\mathbf{r}_{280 / 65}$, except that daily response increased steadily toward the end of lactation (Figure 2). This difference is due to the fact that $\mathrm{P}_{280 / 65}$ aims to reduce $\mathrm{EBV}$ from d 5 to 65 and increase EBV from d 66 to 280, whereas $r_{280 / 65}$ is designed to reduce $D_{65}$ and increase $D_{280}$ so that EBV continues to increase beyond DIM 280 as correlated response. This response confirms the above graphic depiction that $\mathrm{P}_{280 / 65}$ places greater weight on $\mathrm{D}_{5-65}$ than on $\mathrm{D}_{66-280}$, whereas $\mathrm{r}_{280 / 65}$ places greater weight on $\mathrm{D}_{280}$ than on $D_{65}$ to increase the respective value of the selection criteria. The responses in lactation milk caused by $\mathrm{r}_{280 / 65}$ and $\mathrm{P}_{280 / 65}$ are similar ( 36.8 vs. $34.2 \mathrm{~kg} \mathrm{EBV}$ ). The responses in persistency $(k)$ from $\mathrm{r}_{280 / 65}$ and $\mathrm{P}_{280 / 65}$ are -0.00064 and -0.00053 , respectively (Table 1 ). Criterion $\mathrm{r}_{280 / 65}$ produced a slightly better persistency than $\mathrm{P}_{280 /}$ 65. Criterion $\mathrm{P}_{280 / 65}$ is most effective in decreasing EBV in early lactation and maintaining a rather constant gain in EBV in mid and late lactation. Criterion $\mathrm{EBV}_{\mathrm{L}}$ yielded greater daily responses than the other 4 election criteria $\left(\mathrm{d}_{65-280}, \mathrm{r}_{280 / 65}, \mathrm{P}_{280 / 65}\right.$, and $\left.\mathrm{P} 6\right)$ during the lactation (Figure 2).

Consistently negative response in daily milk from DIM 5 to 215 to selection on $\mathrm{d}_{65-280}$ was the most remarkable because the weighting factor for the reduction of $D_{65}$ in $\mathrm{d}_{65-280}$ is larger than the other criteria as depicted earlier in Figure 1. Average daily genetic gains among 4 stages (DIM 5 to 65, DIM 66 to 170, DIM 171 to 280, and DIM 281 to 305) are shown in Table 3. Average daily genetic gain caused by $\mathrm{d}_{65-280}$ was negative in stage DIM 5 to 65 and then increased steadily with advancing DIM of the lactation. This means an improvement of persistency by selection on $\mathrm{d}_{65-280}$ because average daily genetic gain in the latter stage must be larger than that of the former stage to raise persistency. Criterion $r_{280 / 65}$ consistently increases the average daily genetic gain to the end of lactation, whereas criterion $\mathrm{P}_{280 / 65}$ increases the average 
Table 2. Expected responses to different selection criteria on DIM 5, 30, 60, 65, 90, 120, 180, 240, 280, and 305 (unit $=\mathrm{kg}$ ).

\begin{tabular}{llllll}
\hline & \multicolumn{5}{c}{ Criterion } \\
\cline { 2 - 6 } Response & $\mathrm{D}_{65}^{2}-\mathrm{D}_{280}$ & $\mathrm{D}_{280} / \mathrm{D}_{65}$ & $\mathrm{D}_{66-280} / \mathrm{D}_{5-65}$ & $\mathrm{EBV}_{\mathrm{L}}{ }^{3}$ & $\mathrm{P}^{4}$ \\
\hline$\Delta \mathrm{G}^{1}{ }_{5}$ & -0.0532 & 0.0198 & -0.0421 & 0.0965 & -0.0579 \\
$\Delta \mathrm{G}_{30}$ & -0.1380 & 0.0186 & -0.0074 & 0.1873 & -0.1448 \\
$\Delta \mathrm{G}_{60}$ & -0.1447 & 0.0468 & 0.0435 & 0.2339 & -0.1680 \\
$\Delta \mathrm{G}_{65}$ & -0.1404 & 0.0529 & 0.0518 & 0.2376 & -0.1670 \\
$\Delta \mathrm{G}_{90}$ & -0.1094 & 0.0840 & 0.0896 & 0.2467 & -0.1516 \\
$\Delta \mathrm{G}_{120}$ & -0.0697 & 0.1163 & 0.1238 & 0.2472 & -0.1256 \\
$\Delta \mathrm{G}_{180}$ & -0.0223 & 0.1541 & 0.1563 & 0.2435 & -0.0841 \\
$\Delta \mathrm{G}_{240}$ & 0.0148 & 0.1758 & 0.1653 & 0.2265 & -0.0377 \\
$\Delta \mathrm{G}_{280}$ & 0.0546 & 0.1907 & 0.1655 & 0.1987 & 0.0104 \\
$\Delta \mathrm{G}_{305}$ & 0.0728 & 0.1939 & 0.1566 & 0.1798 & 0.0379 \\
\hline
\end{tabular}

${ }^{1} \Delta \mathrm{G}_{\mathrm{i}}=$ genetic response in DIM i.

${ }^{2} \mathrm{D}_{\mathrm{i}}=\mathrm{EBV}$ on DIM $\mathrm{i}$.

${ }^{3} \mathrm{EBV}_{\mathrm{L}}=$ lactation EBV.

${ }^{4} \mathrm{P} 6=\sum_{\mathrm{i}=65}^{279}\left(\mathrm{D}_{280}-\mathrm{D}_{\mathrm{i}}\right)$.

daily genetic gain up to stage DIM 171 to 280 and then decreases slightly beyond DIM 280 (Table 3; Figure 2). The response pattern exhibited by both $\mathrm{r}_{280 / 65}$ and $\mathrm{P}_{280 / 65}$ indicates that both criteria did result in a better persistency. This is in agreement with graphic interpretation of criterion $\mathrm{P}_{280 / 65}$, which aims to reduce the area of mnac before the peak and increase the area of $a b f c$ beyond the peak in Figure 1. Improved persistency could result in higher milk yield in the last stage of lactation. Keeping high yield toward the end of lactation may not be directly related to long calving interval. Even if relatively high yield is observed in late lactation, cows can be dried for next calving. Daily genetic gains caused by selection on $\mathrm{P}_{280 / 65}$ decreased slightly in the last stage

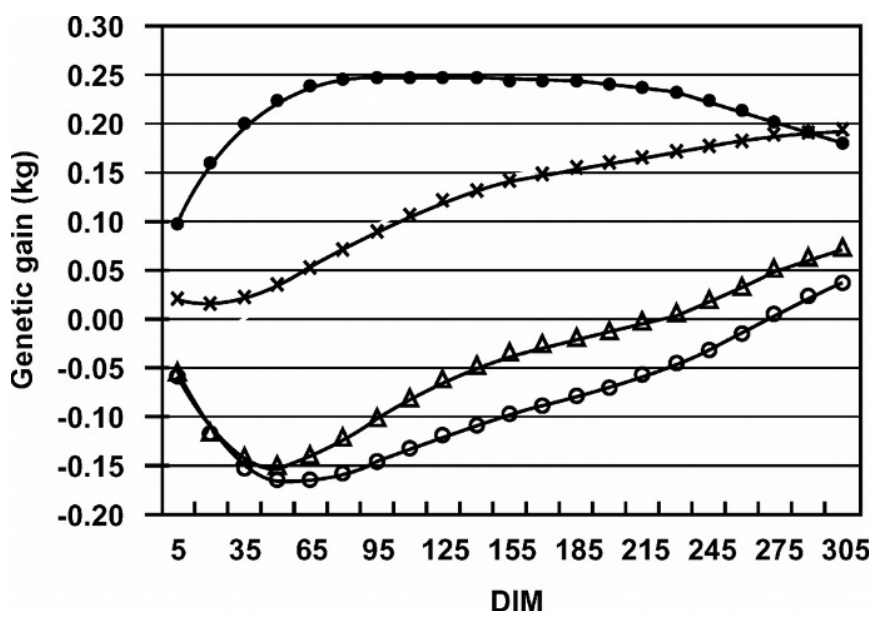

Figure 2. Genetic gains from 5 selection criteria. Legend: 0 $\mathrm{EBV}_{\mathrm{L}}$ (lactation EBV), $\bigcirc=\mathrm{P} 6\left(\sum_{\mathrm{i}=65}^{279}\left(\mathrm{D}_{280}-\mathrm{D}_{\mathrm{i}}\right)\right), \Delta=\mathrm{d}_{65-280}\left(\mathrm{D}_{65^{-}}\right.$ $\left.\mathrm{D}_{280}\right), \times=\mathrm{r}_{280 / 65}\left(\mathrm{D}_{280} / \mathrm{D}_{65}\right)$ and $-=\mathrm{P}_{280 / 65}\left(\mathrm{D}_{66 \sim \mathrm{d} 280} / \mathrm{D}_{5 \sim 65}\right)$. of lactation (stage DIM $281 \sim 305$ ). Further study is needed regarding how to strike a balance between improved persistency and optimum calving interval. The daily genetic loss in early lactation from $\mathrm{P}_{280 / 65}$ would alleviate stress in early lactation. Average daily response to selection on $\mathrm{EBV}_{\mathrm{L}}$ decreased from peak period to the end of lactation, meaning a decrease in persistency (Table 3; Figure 2). Criterion P6 decreased the area of cef (Figure 1) to improve persistency by reducing the genetic gain at the peak (DIM 65) by $0.17 \mathrm{~kg}$ EBV and by increasing genetic gain at DIM 280 by $0.01 \mathrm{~kg}$ EBV (Table 2). P6 showed similar trend in persistency to $\mathrm{d}_{65-280}$ (Figure 2 ), but the former incurred greater genetic loss in lactation milk than the latter.

\section{CONCLUSIONS}

Five selection criteria (lactation EBV, P6, differential daily EBV, ratio of daily EBV, and ratio of partial lactation EBV) were compared in terms of genetic changes in lactation milk and persistency. An objective measure of persistency (parameter $k$ ) free from the effect of lactation milk was presented. Persistency increases when $k<$ 0 and decreases when $k>0$. The effectiveness of selection criteria in improving persistency is in the order of $\mathrm{d}_{65-280}, \mathrm{P} 6, \mathrm{r}_{280 / 65}, \mathrm{P}_{280 / 65}$, and $\mathrm{EBV}_{\mathrm{L}}$. The improvement of lactation milk is in order of $\mathrm{EBV}_{\mathrm{L}}, \mathrm{r}_{280 / 65}, \mathrm{P}_{280 / 65}, \mathrm{~d}_{65-280}$, and P6. Selection based on $\mathrm{EBV}_{\mathrm{L}}$ achieved the greatest genetic gain in lactation milk, but resulted in the worst persistency as compared with the other 4 criteria designed mainly for improvement of persistency. Both $\mathrm{d}_{65-280}$ and P6 achieved high persistency at the expense of lactation milk. Selection on $\mathrm{P}_{280 / 65}$ or $\mathrm{r}_{280 / 65}$ improved both lactation milk and persistency simultaneously. However, it merits further study to determine the rela- 
Table 3. Expected responses in average daily genetic gains among 4 stages (unit $=\mathrm{kg}$ ).

\begin{tabular}{|c|c|c|c|c|c|}
\hline \multirow[b]{2}{*}{ Responses } & \multicolumn{5}{|c|}{ Criterion } \\
\hline & $\mathrm{D}_{65}^{2}-\mathrm{D}_{280}$ & $\mathrm{D}_{280} / \mathrm{D}_{65}$ & $\mathrm{D}_{66-280} / \mathrm{D}_{5-65}$ & $\mathrm{EBV}_{\mathrm{L}}{ }^{3}$ & $\mathrm{P} 6^{4}$ \\
\hline$\Delta \mathrm{G}_{5-65 / 61}^{1}$ & -0.1282 & 0.0267 & 0.0022 & 0.1879 & -0.1394 \\
\hline$\Delta \mathrm{G}_{66-170 / 105}$ & -0.0768 & 0.1099 & 0.1154 & 0.2457 & -0.1283 \\
\hline$\Delta \mathrm{G}_{171-280 / 110}$ & 0.0075 & 0.1707 & 0.1627 & 0.2290 & -0.0472 \\
\hline$\Delta \mathrm{G}_{281-305 / 25}$ & 0.0654 & 0.1932 & 0.1618 & 0.1885 & 0.0255 \\
\hline
\end{tabular}

tive economic weights between these 2 traits for index selection. It is also important to investigate the impact of higher persistency on lifetime production and lifetime profit.

\section{ACKNOWLEDGMENTS}

The authors thank M. H. Pool for kindly providing the genetic covariance matrix of RR coefficients estimated for a 335-d lactation period. Helpful discussion with $\mathrm{H}$. Iwaisaki and constructive comments of an anonymous reviewer are gratefully appreciated.

\section{REFERENCES}

Butler, W. R., and R. D. Smith. 1989. Interrelationships between energy balance and postpartum reproductive function in dairy cattle. J. Dairy Sci. 72:767-783.

Danell, B. 1982. Studies on lactation yield and individual test-day yields of Swedish dairy cows. III. Persistency of milk yield and its correlation with lactation yield. Acta Agric. Scand. 32:93-101.

de Vries, M. J., S. van Der Beek, L. M. T. E. Kaal-Lansbergen, W. Ouweltjes, and J. B. M. Wilmink. 1999. Modeling of energy balance in early lactation and the effect of energy deficits in early lactation on first detected estrus postpartum in dairy cows. J. Dairy Sci. 82:1927-1934.

Dekkers, J. C. M., J. Jamrozik, J. H. ten Hag, L. R. Schaeffer, and A. Weersink. 1996. Genetic and economic evaluation of persistency in dairy cattle. Interbull Bull. 12:97-102.

Dekkers, J. C. M., J. H. ten Haag, and A. Weersink. 1998. Economic aspects of persistency of lactation in dairy cattle. Livest. Prod. Sci. $53: 237-252$.

Ferris, T. A., I. L. Mao, and C. R. Anderson. 1985. Selecting for lactation curve and milk yield in dairy cattle. J. Dairy Sci. 68:1438-1448.

Gengler, N. 1996. Persistency of lactation yields: A review. Interbull Bull. 12:87-96.

ICAR. 2003. Yearly Inquiry on the Situation of Milk Recording in Member Countries. Available at: www.icar.org/yearly.htm.

Jakobsen, J. H., P. Madsen, J. Jensen, J. Pedersen, L. G. Christensen, and D. A. Sorensen. 2002. Genetic parameters for milk production and persistency for Danish Holsteins estimated in random regression models using REML. J. Dairy Sci. 85:1607-1616.
Jamrozik, J., G. Jansen, L. R. Schaeffer, and Z. Liu. 1998. Analysis of persistency of lactation calculated from a random regression test day model. Interbull Bull. 17:64-69.

Jamrozik, J., L. R. Schaeffer, and J. C. M. Dekkers. 1997. Genetic evaluation of dairy cattle using test day yields and random regression model. J. Dairy Sci. 80:1217-1226.

Lin, C. Y. 1980. Relative efficiency of selection methods for improvement of feed efficiency. J. Dairy Sci. 63:491-494.

Lin, C. Y., and K. Togashi. 2002. Simultaneous improvement of lactation milk and persistency. In Proc. 7th World Congr. Genet. Appl. Livest. Prod., Montpellier, France. CD-ROM Commun. 09-05.

Loeffler, S. H., M. J. de Vries, and Y. H. Schukken. 1999. The effects of time of disease occurrence, milk yield, and body condition on fertility of dairy cows. J. Dairy Sci. 82:2589-2604.

Mood, A. M., F. A. Graybill, and D. C. Boes. 1987. Introduction to the Theory of Statistics. McGraw-Hill, Singapore.

Pool, M. H., L. L. G. Janss, and T. H. E. Meuwissen. 2000. Genetic parameters of Legendre polynomials for first parity lactation curves. J. Dairy Sci. 83:2640-2649.

Pool, M. H., and T. H. E. Meuwissen. 2001. Effects of random regression test-day models on EBVs and genetic trends in persistency. Interbull Bull. 27:184-188.

Schaeffer, L. R., and J. C. M. Dekkers. 1994. Random regressions in animal models for test-day production in dairy cattle. Proc. 5th World Congr. Genet. Appl. Livest. Prod., Guelph, Canada. 18:443-446.

Senatore, E. M., W. R. Butler, and P. A. Oltenacu. 1996. Relationships between energy balance and post-partum ovarian activity and fertility in first lactation dairy cows. Anim. Sci. 62:17-23.

Solkner, J., and W. Fuchs. 1987. A comparison of different measures of persistency with special respect to variation of test-day milk yields. Livest. Prod. Sci. 16:305-319.

Swalve, H. H., and N. Gengler. 1999. Genetics of lactation persistency. Occ. Publ. Br. Soc. Anim. Sci. 24:75-82.

Togashi, K., and C. Y. Lin. 2003. Modifying the lactation curve to improve lactation milk and persistency. J. Dairy Sci. 86:1487-1493.

Wood, P. D. P. 1967. Algebraic model of the lactation curve in cattle. Nature 216:164-165.

Zimmermann, E., and H. Sommer. 1973. Zum Laktationsverlauf von Kuhen in Hochleistung-sherden und dessen Beeinflussung durch nichterbliche Faktoren. Zuchtungskunde 45:75-88.

Zwald, N. R., K. A. Weigel, W. F. Fikse, and R. Rekaya. 2001. Characterization of dairy production systems in countries that participate in the international bull evaluation service. J. Dairy Sci. 84:2530-2534. 